BMC

Neuroscience

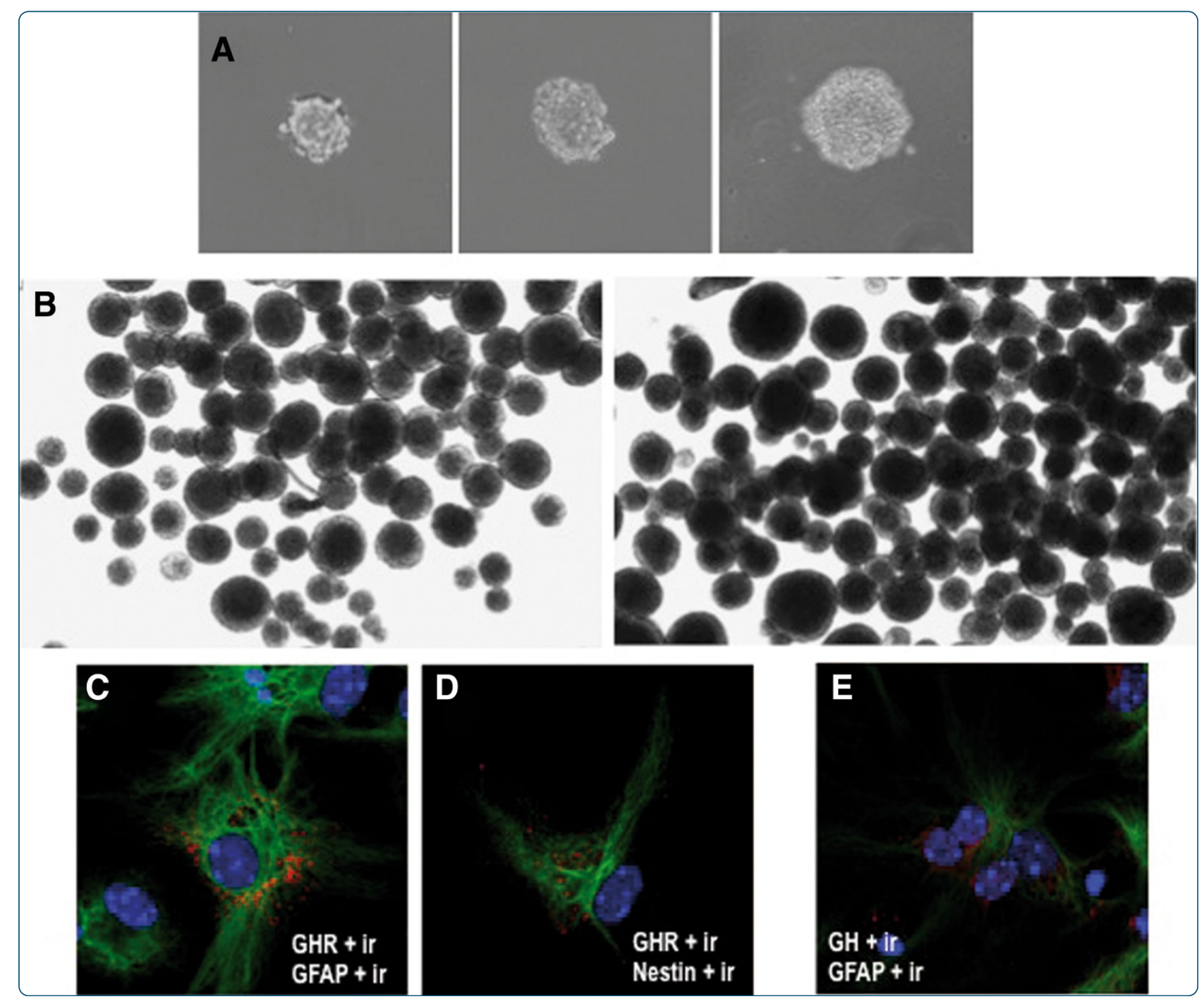

Growth hormone pathways signaling for cell proliferation and survival in hippocampal neural precursors from postnatal mice

Devesa et al.

() Biomed Central 


\title{
Growth hormone pathways signaling for cell proliferation and survival in hippocampal neural precursors from postnatal mice
}

\author{
Pablo Devesa ${ }^{1,3}$, Fabienne Agasse $^{2}$, Sara Xapelli², Cristina Almengló ${ }^{1,3}$, Jesús Devesa ${ }^{1,3^{*}}$, Joao O Malva ${ }^{2}$
} and Víctor M Arce ${ }^{1 *}$

\begin{abstract}
Background: Accumulating evidence suggests that growth hormone $(\mathrm{GH})$ may play a major role in the regulation of postnatal neurogenesis, thus supporting the possibility that it may be also involved in promoting brain repair after brain injury. In order to gain further insight on this possibility, in this study we have investigated the pathways signaling the effect of $\mathrm{GH}$ treatment on the proliferation and survival of hippocampal subgranular zone (SGZ)-derived neurospheres.

Results: Our results demonstrate that GH treatment promotes both proliferation and survival of SGZ neurospheres. By using specific chemical inhibitors we have been also able to demonstrate that GH treatment promotes the activation of both Akt-mTOR and JNK signaling pathways, while blockade of these pathways either reduces or abolishes the GH effects. In contrast, no effect of GH on the activation of the Ras-ERK pathway was observed after $\mathrm{GH}$ treatment, despite blockade of this signaling path also resulted in a significant reduction of $\mathrm{GH}$ effects. Interestingly, SGZ cells were also capable of producing GH, and blockade of endogenous GH also resulted in a decrease in the proliferation and survival of SGZ neurospheres.

Conclusions: Altogether, our findings suggest that $\mathrm{GH}$ treatment may promote the proliferation and survival of neural progenitors. This effect may be elicited by cooperating with locally-produced GH in order to increase the response of neural progenitors to adequate stimuli. On this view, the possibility of using $\mathrm{GH}$ treatment to promote neurogenesis and cell survival in some acquired neural injuries may be envisaged.
\end{abstract}

Keywords: GH, Neurogenesis, Apoptosis, Brain injury, Akt-mTOR, JNK

\section{Background}

Since the discovery of newly generated neurons in the fully developed mammalian brain [1], research on adult neurogenesis has become one of the major goals of neuroscience. Under unperturbed conditions, postnatal neurogenesis is particularly important in two well-defined anatomical regions of the central nervous system (CNS): the subventricular zone (SVZ) lining the lateral walls of the anterior lateral ventricles; and the subgranular zone (SGZ) of the dentate gyrus (DG) of the hippocampus [2-5]. The neural stem cells (NSCs) stored within these

\footnotetext{
* Correspondence: jesus.devesa@usc.es; victor.arce@usc.es

${ }^{1}$ Department of Physiology, School of Medicine, University of Santiago de Compostela, 15710 Santiago de Compostela, Spain

${ }^{3}$ Medical Center Proyecto Foltra, Travesía de Montouto 24, 15886 Teo, Spain Full list of author information is available at the end of the article
}

neurogenic niches continuously self-renew and differentiate into multiple neural lineages, thus allowing the equilibrium between cell loss and cell replacement while maintaining the NSC pool [6]. In addition, accumulating evidence indicates that increased postnatal neurogenesis may be also observed in response to acute injury to the CNS, thus suggesting that new neurons may be generated in order to replace those lost owing to tissue wound and therefore contribute to the healing [7-11].

However, regardless of the time elapsed since the first discovery of postnatal mammalian neurogenesis, key information is still lacking about the regulatory mechanisms controlling the self-renewal and differentiation processes [12]. Postnatal neurogenesis has been shown to be regulated by a number of extrinsic factors such as pharmacological 
stimuli, an enriched environment or physical exercise $[2,13,14]$. In addition, postnatal neurogenesis is regulated by numerous hormones, among which the growth hormone (GH)-insulin-like growth factor-1 (IGF1) system seems to play a pivotal role [15]. The existence of important neurogenic (and neurotrophic) actions of $\mathrm{GH}$ in the adult brain has been demonstrated both in humans and laboratory animals [16-21]. Furthermore, GH has been shown to potentiate the neurogenesis induced in response to brain injury [22-24], thus leading to the possibility of using the hormone in the treatment of some neural diseases. However, little is known about the mechanisms underlying the neurogenic actions of $\mathrm{GH}$, although they may depend, at least in part, on the stimulation of the proliferation, differentiation and survival of neural precursors. Therefore, this study was designed to investigate to role of $\mathrm{GH}$ in the regulation of the proliferation and survival of cultured neurospheres obtained from the DG of postnatal mice, as well as the molecular mechanisms underlying those effects.

\section{Results}

Establishment and characterization of SGZ-derived neurosphere cultures

SGZ-derived neurospheres obtained from neonatal (9 day old) mice were able to grow and give rise to new neurospheres upon passaging, thus demonstrating their capacity of self-renewal (Figures 1A and B, see also Table 1). In addition, these neurospheres were able to generate either GFAP- nestin- or O4-positive cells upon differentiation (data not shown). By using a polyclonal anti-GHR antibody we found the presence of GHR immunoreactivity in cells co-expressing either Nestin (Figure 1C) or GFAP (Figure 1D). In contrast, we have been unable to find GHR immunoreactivity in O4-positive cells (data not shown). $\mathrm{GH}$ immunoreactivity was also observed in neurosphere cells co-expressing GFAP (Figure 1D).

\section{GH treatment promotes the proliferation and survival of SGZ-derived neurospheres}

Treatment of SGZ-derived neurospheres with GH resulted in a significant increase in the amount of BrdU incorporation (Figures 2A and B); an effect that was prevented by treating the cells with the GHR antagonist pegvisomant. Since pegvisomant hinders the binding of GH to its receptor, this finding demonstrates that $\mathrm{GH}$-induced proliferation depends on stimulation of GHR. Interestingly, a significant decline in the proliferation of neurosphere cultures was also observed when pegvisomant was given alone (i.e. in the absence of exogenous GH) (Figures 2A and $\mathrm{B})$. In contrast with these findings, $\mathrm{GH}$ was ineffective in promoting neurosphere proliferation when was given in the absence of EGF and FGF (Figure 2C).

In addition to promote proliferation, $\mathrm{GH}$ treatment was able to significantly reduce the apoptosis in neurosphere

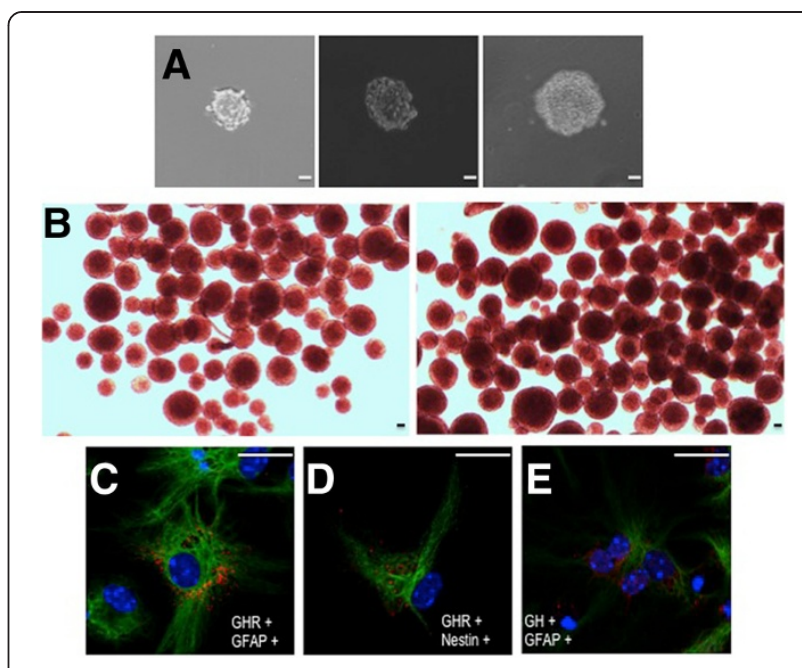

Figure $1 \mathrm{GH}$ and GHR expression in SGZ-derived neurospheres. A) Evolution of neurosphere size after 7 (left), 12 (middle) or 15 (right) days in culture. B) Evolution of neurosphere number after 7-9 (left) or 13-15 (right) days in culture. In both cases, neurospheres were cultured in DMEM containing 1\% Gibco B27 supplement, EGF (10 ng/mL) and FGF2 (10 ng/mL). C to E) SGZ-derived neurospheres express GHR and GH. Neurospheres were cultured for 7 days in DMEM containing 1\% Gibco B27 supplement, and GH, GHR, GFAP and nestin immunoreactivities were detected with specific antibodies. GHR immunoreactivity is shown in red (C, D). GH immunoreactivity

is shown in red (E). GFAP immunoreactivity is shown in green (C, E). Nestin immunoreactivity is shown in green (D). Scale bar $=10 \mu \mathrm{m}$.

cultures (Figure 3). In order to induce cell death, neurosphere cultures were placed in media devoid of EGF and FGF. Under these experimental conditions, the number of apoptotic cells significantly increased with regard to cells growing in defined media (Figure 3), but this was counteracted by treating the cells with $\mathrm{GH}$ (Figure 3). Also in this case, the $\mathrm{GH}$ effect was prevented by treating the cells with pegvisomant, thus demonstrating the involvement of GHR. In concordance with the effect of pegvisomant on cell proliferation, a significant increase in apoptotic cell death was also observed when pegvisomant was given alone (Figure 3).

Role of the Ras-ERK signaling pathway in the proliferative and antiapoptotic effects of GH

The importance of ERK phosphorylation in transducing $\mathrm{GH}$ actions has been previously demonstrated in different cell types $[25,26]$. Therefore, in order to investigate the

Table 1 Evolution of neurosphere size and number

\begin{tabular}{lccc}
\hline A) Days & $\mathbf{7}$ & $\mathbf{1 2}$ & $\mathbf{1 5}$ \\
\hline Neurosphere size $(\mathrm{mm})$ & $23.1 \pm 0.8$ & $32.3 \pm 0.9^{*}$ & $35.1 \pm 1.5^{*}$ \\
\hline B) Days & $\mathbf{7 - 9}$ & $\mathbf{1 3 - 1 5}$ & \\
\hline Neurosphere number & $139.4 \pm 6.4$ & $331.2 \pm 10.0^{\circ}$ &
\end{tabular}

Cells were grown in defined media as described for the indicated times. ${ }^{*}=p<0.01$ vs day $7 ;^{\circ}=p<0.01$ vs day $7-9$. 

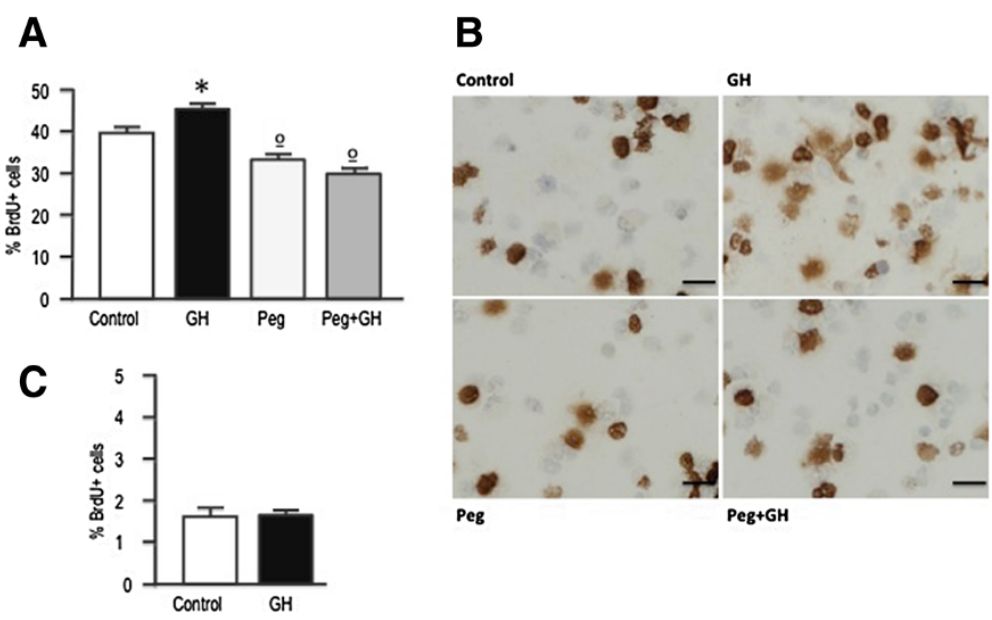

Figure $2 \mathrm{GH}$ treatment promotes the proliferation of SGZ neurospheres. A) Neurospheres growing in defined media were treated for $24 \mathrm{~h}$ with $\mathrm{GH}(500 \mathrm{ng} / \mathrm{mL})$, pegvisomant (Peg, $20 \mu \mathrm{g} / \mathrm{mL})$, or $\mathrm{GH}$ + pegvisomant. Control cells were treated with saline. Four hours before the end of the treatment period cells were given a BrdU pulse $(10 \mu \mathrm{M})$. Neurospheres were then dissociated, cells were collected by centrifugation onto coated cover slips, and BrdU was detected by immunocytochemistry. Each bar represents the mean + SEM of 3 experiments in triplicate. ${ }^{*}=p<0.05$ vs Control; ${ }^{\circ}=p<0.05$ vs Control and GH. B) Representative images of results presented in A. Scale bar $=10 \mu \mathrm{m}$. C) Neurospheres growing in defined media without EGF and FGF2 were treated for $24 \mathrm{~h}$ with GH or saline, and BrdU incorporation was detected as indicated. Each bar represents the mean + SEM of 3 experiments in triplicate.

involvement of this signaling pathway in SGZ-derived neurosphere cultures, we treated them with U0126, a highly specific inhibitor of MEK1/2 that effectively blocks ERK phosphorylation. Blockade of Ras-ERK signaling not only resulted in a prominent inhibition of neurosphere proliferation (Figure 4A), but completely blocked the positive effect of GH on cell proliferation. Similarly, U0126 treatment induced a significant increase in the number of apoptotic cells, although in this case, the effect was partially counteracted by GH treatment (Figure 4B). Surprisingly, and in contrast with previous reports $[25,26]$, we have been unable to find any effect of GH on ERK phosphorylation in cultured SGZ neurospheres (Figures 4C and D).

Role of the Phosphoinositide 3-kinase (PI-3 K)/Akt/mTOR signaling pathway in the proliferative and antiapoptotic effects of $\mathrm{GH}$

The role of the PI-3 K/Akt/mTOR pathway in GH signaling has been also supported by several previous observations [27,28]. Activation of GHR induces the phosphorylation of the GHR-associated protein Insulin

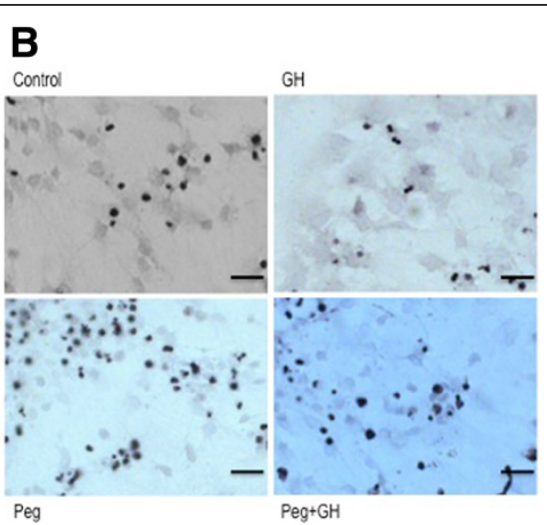

Figure $3 \mathrm{GH}$ treatment prevents apoptosis in SGZ neurospheres. A) Neurospheres growing in defined media were placed in defined media without EGF and FGF2, and $24 \mathrm{~h}$ later treated with $\mathrm{GH}(500 \mathrm{ng} / \mathrm{mL})$, pegvisomant $(20 \mu \mathrm{g} / \mathrm{mL})$, or $\mathrm{GH}$ + pegvisomant for an additional $48 \mathrm{~h}$ period. Control cells were treated with saline. Cell apoptosis was determined by TUNEL staining. Each bar represents the mean + SEM of 3 experiments in triplicate. ${ }^{*}=p<0.05$ vs Control; ${ }^{\circ}=p<0.05$ vs Control and $p<0.01$ vs GH. Basal apoptosis was determined by growing the cells in the defined media (Control + EGF + FGF2). Apoptosis values in this group were significantly lower $(p<0.01)$ than in the other groups. $E=E G F ; F=F G F 2$.

B) Representative images of results presented in A. Scale bar $=10 \mu \mathrm{m}$. 

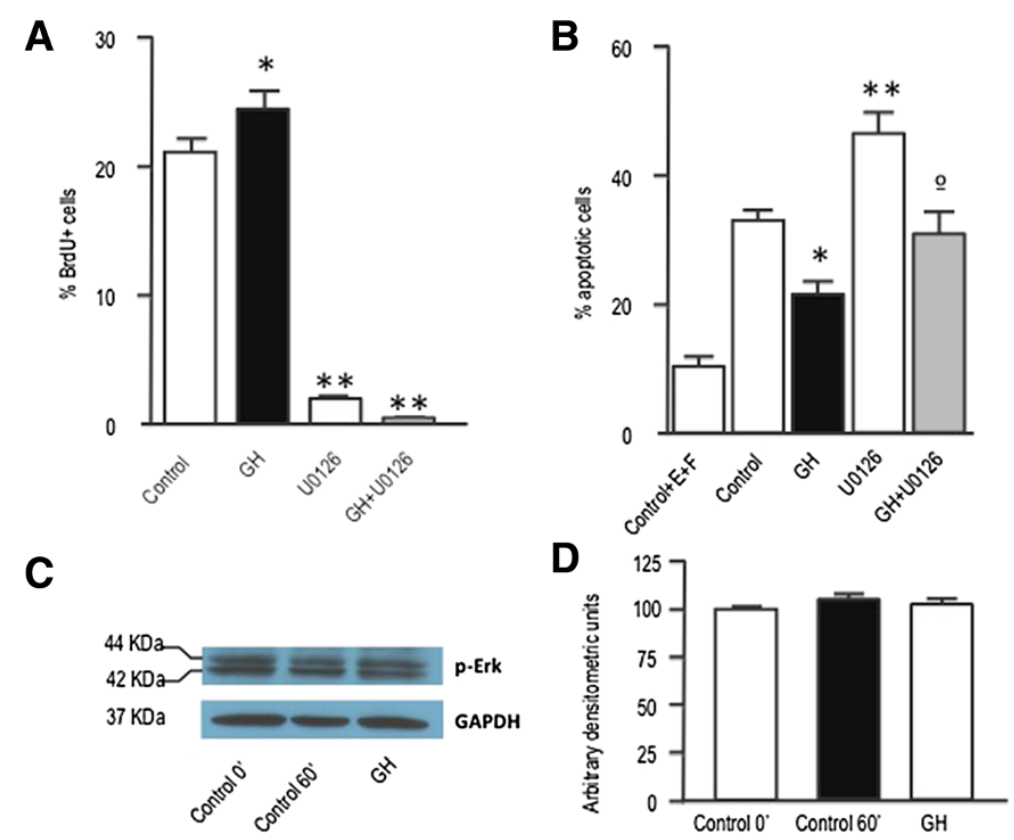

Figure 4 ERK phosphorylation is necessary for neurosphere proliferation and survival. A) Neurospheres growing in defined media were treated for 24 h with GH $(500 \mathrm{ng} / \mathrm{mL})$, U0126 $(20 \mu \mathrm{M})$ or GH + U0126. Control cells were treated with saline. Four hours before the end of the treatment period cells were given a BrdU pulse $(10 \mu \mathrm{M})$. Neurospheres were then dissociated and cells were collected by centrifugation onto coated cover slips, and BrdU was detected by immunocytochemistry. ${ }^{*}=p<0.05$ vs Control; ${ }^{* *}=p<0.001$ vs control and GH. B) Neurospheres were placed into culture plates containing defined media without EGF and FGF2, and $24 \mathrm{~h}$ later treated with GH, U0126 or GH + U0126, for an additional $48 \mathrm{~h}$ period. Control cells were treated with saline. Cell apoptosis was determined by TUNEL staining. Each bar represents the mean + SEM of 3 experiments in triplicate. ${ }^{*}=p<0.01$ vs Control; ${ }^{* *}=p<0.001$ vs control and $\mathrm{GH}^{\circ}{ }^{\circ}=p<0.01$ vs $\mathrm{GH}$. Basal apoptosis was determined by growing the cells in the defined media (Control + EGF + FGF2). Apoptosis values in this group were significantly lower $(p<0.01)$ than in the other groups. $\mathrm{E}=\mathrm{EGF} ; \mathrm{F}=\mathrm{FGF2}$. C) Neurospheres were deposited for $48 \mathrm{~h}$ in slides with defined media without EGF and FGF2, and then treated with GH for 1 h. Phospho ERK and GAPDH immunoreactivities were determined by western blot. D) Densitometric evaluation of results presented in C. Phospho ERK levels are expressed as arbitrary densitometric units and normalized to GAPDH levels.

receptor substrate 1 (IRS1) which, in turn, activates PI$3 \mathrm{~K}$ that promotes Akt phosphorylation. In keeping with those findings, $\mathrm{GH}$ treatment induced a prompt and marked rise in phospho-Akt levels in SGZ-derived neurospheres (Figures 5A and B). Once phosphorylated, Akt activates the phosphoinositide-dependent kinase-1 (PDK1) that, in turns, phosphorylates a number of intracellular targets including mTOR [28] which, reportedly, plays a major role in the regulation of proliferation and survival in different types of cells $[29,30]$. Therefore, in order to assess the involvement of the PI-3 K/Akt/ mTOR pathway on GH actions, we first treated neurosphere cultures with rapamycin, an inhibitor of the mTOR complex 1 (mTORC1). As Figure 5C depicts, treatment with rapamycin significantly reduced the proliferation of neurosphere cultures, and completely abolished the effect of $\mathrm{GH}$. Interestingly rapamycin also induced a significant increase in cell death but, in this case, the effect was partially counteracted by $\mathrm{GH}$ (Figure 5D). In order to further investigate the involvement on Akt stimulation of this effect, cells were also treated with LY294002, a potent inhibitor of PI-3 K. In keeping with previous results in other cell types $[27,31,32]$, inhibition of Akt phosphorylation significantly increased the number of apoptotic cells (Figure 5E) while, as occurred with rapamycin treatment, $\mathrm{GH}$ was able to partially overcome this effect (Figure 5E).

\section{GH-induced JNK phosphorylation is involved in the antiapoptotic effects of GH}

Finally, we investigated the role of JNK in mediating the effects of GH on neurosphere proliferation and survival. In keeping with previous findings in fibroblasts [31] or macrophages [32], GH was able to induce the phosphorylation of JNK in cultured neurospheres (Figures 6A and B). When JNK actions were counteracted by treating the cells with SP600125, a competitive inhibitor of its kinase activity, both proliferation and survival were significantly decreased in neurosphere cultures (Figures $6 \mathrm{C}$ and D). Interestingly, none of these effects could be counteracted by $\mathrm{GH}$ treatment.

\section{Discussion}

This study was designed to investigate the role of $\mathrm{GH}$ on postnatal neurogenesis using a neurosphere culture system. The presence of ongoing neurogenesis in the postnatal 

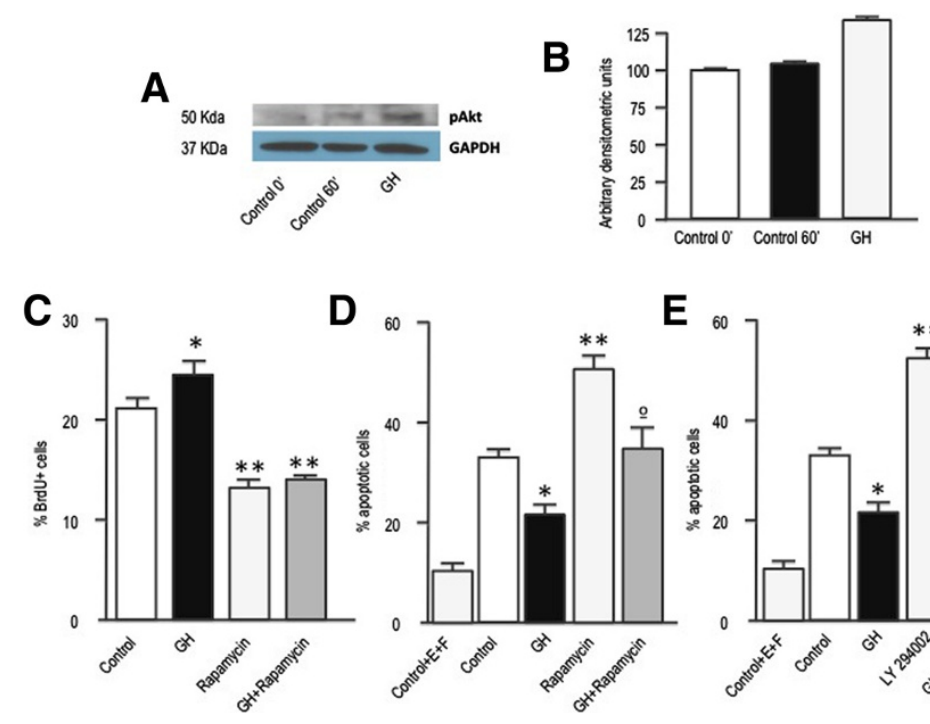

E

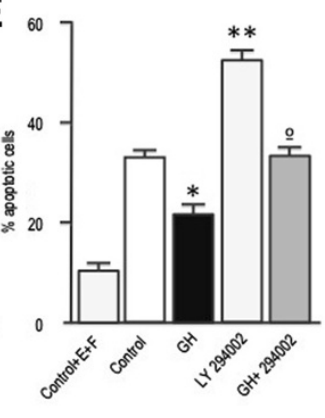

Figure 5 The Pl-3 K/Akt pathway is involved in the antiapoptotic affect of GH. A) Neurospheres were deposited for $48 \mathrm{~h}$ in slides with defined media without EGF and FGF2, and then treated with GH for 1 h. Phospho Akt and GAPDH immunoreactivities were determined by western blot. B) Densitometric evaluation of results presented in A. Phospho Akt levels are expressed as arbitrary densitometric units and normalized to GAPDH levels. C) Neurospheres growing in defined media were treated for $24 \mathrm{~h}$ with saline (Control), GH (500 ng/mL), rapamycin $(20 \mathrm{nM})$, or $\mathrm{GH}+$ rapamycin. Four hours before the end of the treatment period cells were given a BrdU pulse $(10 \mu \mathrm{M})$. Neurospheres were then dissociated and cells were collected by centrifugation onto coated cover slips, and BrdU was detected by immunocytochemistry. ${ }^{*}=p<0.05 \mathrm{vs}$ Control; ${ }^{* *}=p<0.001$ vs Control and GH. D) and E) Neurospheres were placed into culture plates containing defined media without EGF and FGF2, and $24 \mathrm{~h}$ later treated for $48 \mathrm{~h}$ with saline, GH, rapamycin or GH + rapamycin, [D)] or saline, GH, LY $294002(10 \mu \mathrm{M})$ or GH $+\mathrm{LY} 294002$, [E)]. * $=p<0.01$ vs Control; ** $=p<0.01$ vs Control and $p<0.001$ vs $\mathrm{GH}^{*}{ }^{\circ}=p<0.01$ vs $\mathrm{GH}$. In D) and E) basal apoptosis, determined by growing the cells in the defined media (Control $+E+F)$, was significantly lower $(p<0.01)$ than in the other groups. $E=E G F ; F=F G F 2$. Bars $=$ mean $+S E M$ of 3 experiments in triplicate.

mammalian brain, together with the prospect that the stem cell pools present in the adult brain can be directed towards repair of neural injuries has generated much interest for the last several years, see $[19,33]$ for review. Furthermore, since postnatal neurogenesis is regulated by a complex network of signaling molecules and extrinsic factors [12], understanding these mechanisms of control will help to find effective treatments directed towards increase neurogenesis in order to promote brain repair.

$\mathrm{GH}$ has been proposed to play a role on brain repair after injury [34]. Although some of the beneficial effects of GH on brain repair may depend on their neuroprotective actions [33], there is also accumulating evidence indicating that neurogenesis is also stimulated by $\mathrm{GH}$. Thus GH treatment has been demonstrated to promote neurogenesis in different brain areas $[20,23,24,35]$ either under unperturbed conditions $[20,35]$ or in response to brain damage $[23,24]$. Interestingly, GH-induced neurogenesis is potentiated when GH treatment is combined with physical exercise [35,36] or physical rehabilitation [24], thus suggesting that the hormone is not only cooperating with endogenous mechanisms regulating postnatal neurogenesis, but may be even essential to induce the neurogenic response [36]. There is also evidence indicating that $\mathrm{GH}$ increases the frequency of both rodent- and human-derived neurospheres in vitro [37-41; and the present study], thus demonstrating a direct effect of GH on neural precursor cells. Furthermore, in all these cases, GH actions are lost when GHR is absent or inactivated, thus indicating that $\mathrm{GH}$ actions are exerted via activation of GHR; although the possibility that some of $\mathrm{GH}$ actions on neural precursors may depend on the activation of other receptors cannot be ruled out [41].

Once established the importance of GH in the regulation of proliferation and survival of SGZ-derived neurospheres, we next investigated the molecular mechanism underlying these actions. The predominant $\mathrm{GH}$ signal transduction cascade comprises activation of the GHR dimer and phosphorylation of Janus kinase 2 (JAK2). Activated JAK2 then phosphorylates key tyrosine residues on the cytoplasmic domain of the GHR, permitting SH2 domain interactions by signal adaptor proteins that results in docking of signal transducer and activator of transcription 5 (STAT5) for activation by JAK2 $[25,26]$. The triggering of this canonical signaling pathway has been recently demonstrated in neurosphere cells [38], and may be involved in some of the GH actions on these cells. However, phosphorylation of the cytoplasmic domain of the GHR also results in the activation of the Ras/MAPK kinase/ERK pathway; while activated JAK2 is 
A

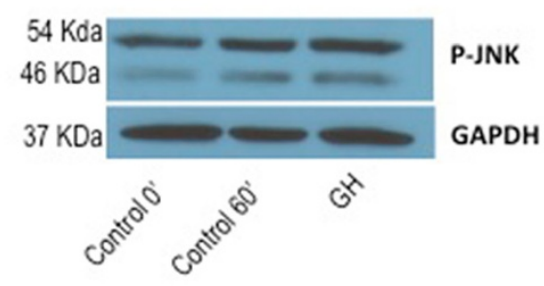

C

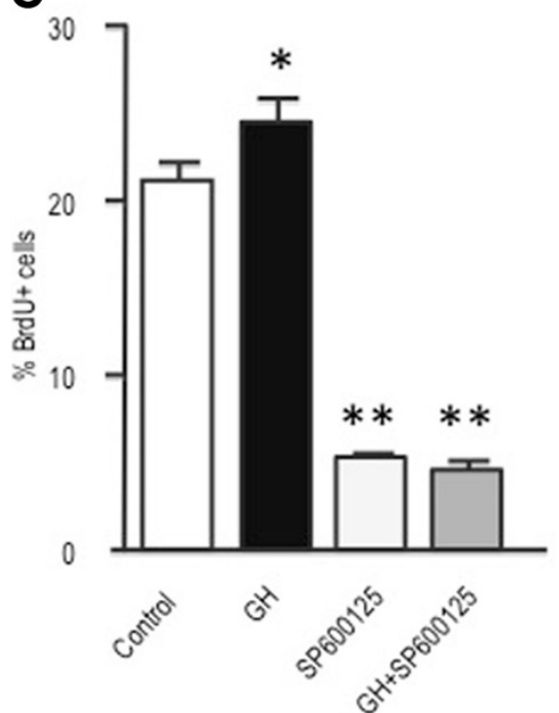

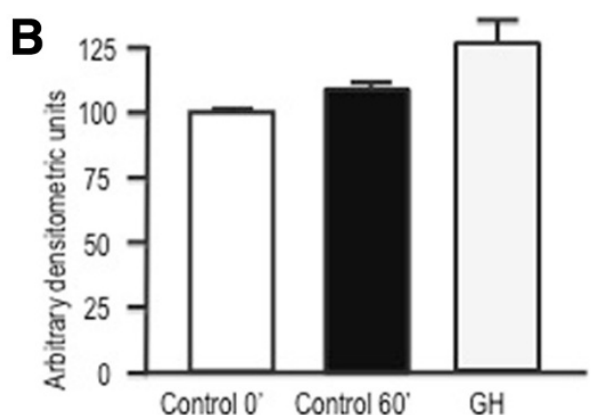

D

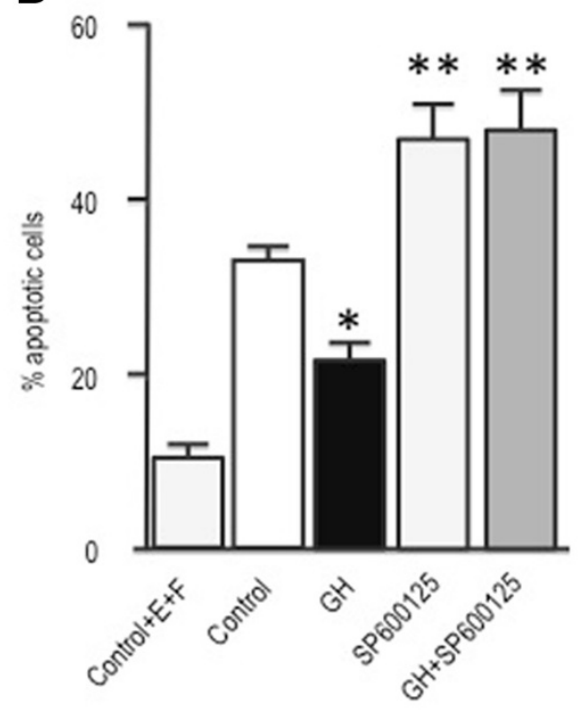

Figure 6 JNK phosphorylation is involved in the proliferative and antiapoptotic affects of GH. A) Neurospheres were deposited for $48 \mathrm{~h}$ in slides with defined media without EGF and FGF2, and then treated with GH for $1 \mathrm{~h}$. Phospho JNK and GAPDH immunoreactivities were determined by western blot. B) Densitometric evaluation of results presented in A. Phospho JNK levels are expressed as arbitrary densitometric units and normalized to GAPDH levels. C) Neurospheres growing in defined media were treated for $24 \mathrm{~h}$ with GH (500 ng/mL), SP600125 (20 $\mu \mathrm{M})$ or SP600125 + GH. Control cells were treated with saline. Four hours before the end of the treatment period cells were given a BrdU pulse $(10 \mu \mathrm{M})$. Neurospheres were then dissociated and cells were collected by centrifugation onto coated cover slips, and BrdU was detected by immunocytochemistry. ${ }^{*}=p<0.05$ vs Control; ${ }^{* *}=p<0.001$ vs Control and GH. D) Neurospheres were placed into culture plates containing defined media without EGF and FGF2, and $24 \mathrm{~h}$ later treated with GH, SP600125 or SP600125 + GH, for an additional $48 \mathrm{~h}$ period. Basal apoptosis was determined by growing the cells in the defined media (Control + EGF + FGF2). Apoptosis values in this group were significantly lower $(p<0.01)$ than in the other groups. ${ }^{*}=p<0.05$ vs Control; ${ }^{* *}=p<0.001$ vs Control and GH. E =EGF; F = FGF2. Bars= mean + SEM of 3 experiments in triplicate.

also able to directly phosphorylate IRS-1/2, facilitating activation of the PI3K/Akt/mTOR pathway [25,26].

Our findings demonstrate that at least two of those signaling pathways, the PI-3 K/Akt/mTOR and JNK module of the MAPK, are activated by GH in cultured neurospheres, thus illustrating the complexity of GHR signaling in these cells. Furthermore, by using selective inhibitors we have been able to demonstrate that, despite these signaling pathways may be important in mediating the GH effects on cell proliferation, they appear to exert a more essential role in the regulation of cell survival. There are several types of evidences supporting our hypothesis. First, GH was able to partially overcome the effect of ERK inhibition on cell survival, while its effect on cell proliferation was completely abrogated under these circumstances. The ability of GH to promote cell survival in the absence of ERK signaling indicates that $\mathrm{GH}$ is able to deliver a survival signal that is independent on Ras/ERK pathway activation. In contrast, Ras/ERK signaling is necessary for the GH effect on neurosphere proliferation indicating that, in keeping with previous reports $[41,42], \mathrm{GH}$ is neither sufficient nor necessary for neurosphere proliferation.

Second, GH treatment also partially counteracted the negative effect of rapamycin on cell survival, but did not modify rapamycin-induced inhibition of cell proliferation. Interestingly, mTOR has been shown to be relevant for EGF-dependent proliferation of neural precursors 
[43], further supporting our hypothesis regarding a minor role of $\mathrm{GH}$ on the regulation of neurosphere proliferation. Furthermore, mTOR is present in two distinct complexes: mTOR complex 1 (mTORC1) and mTOR complex 2 (mTORC2) [30,44]. Since only mTORC1 is inhibited by rapamycin, the possibility exists that $\mathrm{GH}$ actions on cell survival may depend, at least in part, on the rapamycin-insensitive mTORC2 complex, as occurs with insulin [45]. Another possible mechanism, not excluding the former, is that GH may overcome the effect of rapamycin treatment via the stimulation of survival signals that do not depend on the PI-3 K/Akt/mTOR pathway. In this regard, it is interesting to indicate that the ability of $\mathrm{GH}$ to prevent apoptosis was preserved in the presence of PI-3 K inhibition, thus suggesting that Akt activation does not play a major anti-apoptotic role in these cells.

In contrast with these findings, $\mathrm{GH}$ effects on both cell proliferation and survival were completely inhibited when the phosphorylation of JNK was blocked. JNKs are members of the MAPK family that are activated by a variety of environmental stresses, inflammatory cytokines and, in some instances, by growth factors and GPCR (G protein-coupled receptor) agonists [46]. Once activated, the JNK pathway regulates numerous cellular responses including cell proliferation and survival, together with different aspects of neural development [47-50]. Therefore, the fact that blockade of JNK signaling completely inhibited both the proliferation and survival of SVZ-derived neurospheres, indicates that this pathway plays a major role in the regulation of the cellular fate of these cells. Furthermore, the fact that both $\mathrm{GH}$-induced proliferation and survival are also blocked under these experimental conditions, together with the ability of GH to promote JNK phosphorylation, indicates that the JNK pathway is a key component of the signaling machinery activated by GH in SVZ-derived neurospheres. To our knowledge, this is the first time to demonstrate the capacity of $\mathrm{GH}$ to induce the phosphorylation of JNK in neural cells. To the present, GHinduced JNK phosphorylation has been demonstrated in macrophages [34], in NIH 3 T3 fibroblasts [33], and also in chinese hamster ovary cells stably transfected with rat GH receptor cDNA [51]. However, GH has been shown to reduce both basal and doxorubicin-stimulated JNK transcriptional activity and phosphorylation in both MDA-MB-231 and MCF7 cells [52], thus demonstrating the complexity of GH-mediated JNK regulation.

Finally, it is noteworthy to indicate that blockade of $\mathrm{GH}$ signaling was able to induce a decrease in neurosphere proliferation and survival even in cells not receiving $\mathrm{GH}$ treatment. This finding, together with the existence of $\mathrm{GH}$ expression in cultured neurospheres ([41]; and the present report), suggests the existence of an endogenous $\mathrm{GH}$ axis regulating the proliferation and apoptosis of neural progenitors. Up to now, the existence of GH immunoreactivity has been reported in several brain areas that include germinal regions of the embryonic brain [53], as well as brain regions involved in postnatal neurogenesis [54-56]. Furthermore, GH gene expression within these areas is increased by factors known to increase neurogenesis such as learning, exercise or estrogen administration (37; 54, 55), while such increase is not observed in GHR-/- animals (37). Altogether, these findings lead to the possibility that $\mathrm{GH}$ treatment is, in fact, cooperating with locally-produced $\mathrm{GH}$ in increasing the proliferation of neural progenitors in response to adequate stimuli. In this regard, it is interesting to note that we have previously found that $\mathrm{GH}$ is expressed in rat hippocampal progenitors, and that $\mathrm{GH}$ expression increases after neurotoxic damage (23). Therefore, it is tempting to speculate that, this locallyproduced $\mathrm{GH}$ may cooperate with the exogenous hormone in promoting neurogenesis and cell survival in response to brain injury.

\section{Conclusions}

Altogether, these findings lead to the possibility that $\mathrm{GH}$ treatment is, in fact, cooperating with locally-produced $\mathrm{GH}$ in increasing the proliferation and survival of neural progenitors in response to adequate stimuli. In this regard, the fact that increased GH expression has been detected in hippocampal progenitors after neurotoxic damage [23] suggests that endogenous and exogenous $\mathrm{GH}$ may also cooperate in promoting neurogenesis and cell survival in response to brain injury.

\section{Methods}

\section{SGZ cultures and treatments}

All animal procedures were carried out in accordance with European Union guidelines for the care and use of laboratory animals and they were approved by the Ethics committees of the Universities of Santiago de Compostela and Coimbra. SGZ cells were obtained from 9-dayold C57BL/6 donor mice as previously described [25]. Briefly, brains were removed under sterile conditions and placed in calcium- and magnesium-free Hanks' balanced salt solution (Life Technologies Corporation, Carlsbad, CA). Sagittal brain sections (350 $\mu$ m-thick) prepared with a McIlwain tissue chopper were used to dissect SGZ fragments. Fragments were then digested in $0.025 \%$ trypsin (Life Technologies Corporation) and $0.265 \mathrm{mM}$ EDTA (Life Technologies Corporation) for 10 minutes at $37^{\circ} \mathrm{C}$, and gently dissociated with a $1000 \mathrm{~mL}$ plastic pipette tip. The resulting cell suspension was diluted in Dulbecco's modified Eagle's medium (DMEM) supplemented with $100 \mathrm{U} / \mathrm{mL}$ penicillin, $100 \mu \mathrm{g} / \mathrm{mL}$ streptomycin, 1\% Gibco B27 supplement, $10 \mathrm{ng} / \mathrm{mL}$ epidermal 
growth factor (EGF), and $10 \mathrm{ng} / \mathrm{mL}$ basic fibroblast growth factor 2 (FGF2) (defined media; all from Life Technologies Corporation). Cells were then plated on uncoated dishes (Corning Incorporated, Corning, NY) at a density of 3,000 cells per $\mathrm{cm}^{2}$ and maintained at $37^{\circ} \mathrm{C}$ in a $5 \% \mathrm{CO}_{2}$ atmosphere in order to allow neurosphere development. Ten to 12 days after plating, the SGZ-derived neurospheres were collected and placed in fresh DMEM and used for cell proliferation studies. In order to induce cell apoptosis, neurosphere cells were placed in DMEM supplemented with 100 $\mathrm{U} / \mathrm{mL}$ penicillin, $100 \mu \mathrm{g} / \mathrm{mL}$ streptomycin and $1 \%$ Gibco B27 supplement. Further experimental details are provided in the corresponding figure legend.

Recombinant human GH (Humatrope) was obtained from Eli Lilly and Company (Madrid, Spain); pegvisomant (Somavert), an antagonist of GH receptor (GHR), was obtained from Pfizer (Madrid, Spain); the extracellular signal-regulated kinase (ERK) inhibitor U0126, the mammalian target of rapamycin (mTOR) inhibitor rapamycin, and the c-Jun N-terminal kinase (JNK) inhibitor SP600125 were purchased from Sigma-Aldrich (Madrid, Spain). The PI-3 K inhibitor LY 294002 was purchased from Promega (Madison, WI).

\section{Immunofluorescence}

After fixation in 4\% PFA for 30 minutes at room temperature, SGZ cells were permeabilized, and nonspecific binding sites were blocked with $0.25 \%$ Triton X-100 and $3 \%$ BSA for 30 minutes at room temperature. SGZ cells were then incubated overnight at $4^{\circ} \mathrm{C}$ with the following primary antibodies: polyclonal anti-GHR (Abcam, Cambridge, MA; dilution 1:500), polyclonal anti-GH (Abcam; dilution 1:200), monoclonal anti-glial fibrillary acidic protein (GFAP) (Cell Signaling Technology, Danvers, MA; dilution 1:500), monoclonal anti-nestin (EMD Millipore Corporation, Billerica, MA; dilution 1:200), monoclonal anti-O4 (EMD Millipore Corporation; dilution 1:200). Coverslips were then rinsed in PBS and incubated for 1 hour at room temperature with the appropriate secondary antibodies: anti-rabbit IgG labeled with Alexa Fluor 488 (1:200) or with Alexa Fluor 594 (1:200), or anti-mouse IgG labeled with Alexa Fluor 594 (1:200) (all from Life Technologies). After an additional rinse in PBS, cell nuclei were stained with Hoechst 33342 (Life Technologies, $2 \mu \mathrm{g} / \mathrm{mL}$ in PBS containing $0.25 \% \mathrm{BSA}$ ) for 5 minutes at room temperature. Finally, the preparations were mounted using Dako-Cytomation fluorescent medium (DakoCytomation, Carpinteria, CA). Negative controls without primary antibody application showed lack of specific immunoreactivity with minimum background staining (data not shown). Fluorescent images were recorded using a confocal microscope (LSM 510 Meta; Carl Zeiss, Gottingen, Germany) or an Axioskop 2 Plus fluorescent microscope (Carl Zeiss).

\section{Cell proliferation studies}

To assess cell proliferation, neurosphere cells growing in defined media received a treatment for 24 hours and were exposed to $10 \mu \mathrm{M}$ 5-bromo-2'-deoxyuridine (BrdU) (Sigma-Aldrich) for the last 4 hours. Cultures were then fixed in 4\% PFA for 30 minutes and, after extensive rinsing (30 minutes in 0.15 M PBS, at room temperature), BrdU was unmasked by successive passages in: $1 \%$ Triton X-100 for 30 minutes at room temperature, ice-cold $0.1 \mathrm{M} \mathrm{HCl}$ for 20 minutes, and $2 \mathrm{M} \mathrm{HCl}$ for 40 minutes at $40^{\circ} \mathrm{C}$. Following neutralization in sodium borate buffer $(0.1 \mathrm{M}$ $\mathrm{Na}_{2} \mathrm{~B}_{4} \mathrm{O}_{7} \cdot 10 \mathrm{H}_{2} \mathrm{O}, \mathrm{pH}$ 8.5; Sigma-Aldrich) for 15 minutes at room temperature, slices were rinsed in PBS, and nonspecific binding sites were blocked with $3 \%$ bovine serum albumin (BSA; Sigma-Aldrich) and 0.3\% Triton X-100 for 30 minutes at room temperature. SGZ cultures were then incubated overnight at $4^{\circ} \mathrm{C}$ with a primary anti-BrdU antibody (EMD Millipore Corporation; dilution 1:50) in PBS containing $0.1 \%$ Triton X-100 and 0.3\% BSA. After rinsing in PBS, cells were incubated with a secondary antibody labeled with Alexa Fluor 594 (Life Technologies, dilution 1:200) for 1 hour at room temperature. After an additional rinse in PBS, cell nuclei were stained with Hoechst 33342 (Life Technologies, $2 \mu \mathrm{g} / \mathrm{mL}$ in PBS containing $0.25 \%$ BSA) for 5 minutes at room temperature. Finally, the preparations were mounted using DakoCytomation fluorescent medium (DakoCytomation). Fluorescent images were recorded using a confocal microscope (LSM 510 Meta; Carl Zeiss) or an Axioskop 2 Plus fluorescent microscope (Carl Zeiss). For each well, 8 random fields were photographed and BrdU + cells were scored.

\section{Cell survival studies}

Cell apoptosis was evaluated by terminal deoxynucleotidyl transferase dUTP nick-end labeling (TUNEL), as previously described [57]. Briefly, permeabilized cells were incubated in terminal deoxy-nucleotidyl transferase buffer $(0.25 \mathrm{U} / \mu \mathrm{l}$ terminal transferase, $6 \mu \mathrm{M}$ biotinylated dUTP, pH 7.5; all from Roche Farma, S.A, Madrid, Spain) for 1 hour 30 minutes at $37^{\circ} \mathrm{C}$ in a humidified chamber. The enzymatic reaction was stopped by 15 minutes of incubation in $300 \mathrm{mM} \mathrm{NaCl}$ (Sigma-Aldrich) and $30 \mathrm{mM}$ sodium citrate buffer (Sigma-Aldrich). Following an additional rinse in PBS, cultures were incubated for 30 minutes at room temperature with the avidin-biotin-peroxidase complex (1:100; Vector Laboratories, Burlingame, CA). Peroxidase activity was revealed by the $3,3^{\prime}$-diaminobenzidine chromogen (0.025\%; Sigma-Aldrich) intensified with $0.08 \% \mathrm{NiCl}_{2}$ in $30 \mathrm{mM}$ Tris- $\mathrm{HCl}(\mathrm{pH} 7.6)$ buffer containing $0.003 \% \mathrm{H}_{2} \mathrm{O}_{2}$. The cell preparations were then dehydrated in ethanol (70\%, 2 minutes; 80\%, 2 minutes; 90\%, 2 minutes; 95\%, 2 minutes; 100\%, 2 minutes), cleared in xylene (3 minutes), and mounted using DEPEX mounting medium (Sigma-Aldrich). Photomicrographs of TUNEL 
were recorded using a digital camera (Axiocam HRC; Carl Zeiss) adapted to an Axioskop 2 Plus fluorescent microscope (Carl Zeiss). For each well, 8 random fields were photographed and positive cells were scored.

\section{Western blot}

For phospho-ERK, phospho-Akt and phospho-JNK determination, neurospheres were maintained for 12-13 days in DMEM supplemented with $100 \mathrm{U} / \mathrm{mL}$ penicillin, $100 \mu \mathrm{g} / \mathrm{mL}$ streptomycin, 1\% Gibco B27 supplement, EGF $(10 \mathrm{ng} / \mathrm{mL})$, and FGF2 $(10 \mathrm{ng} / \mathrm{mL})$; and then placed in plates containing DMEM supplemented with $100 \mathrm{U} / \mathrm{mL}$ penicillin, $100 \mu \mathrm{g} / \mathrm{mL}$ streptomycin and 1\% Gibco B27 supplement for $12 \mathrm{~h}$. Finally, the medium was replaced with fresh DMEM supplemented with $100 \mathrm{U} / \mathrm{mL}$ penicillin, $100 \mu \mathrm{g} / \mathrm{mL}$ streptomycin and 0.1\% Gibco B27 supplement, and incubated for an additional $12 \mathrm{~h}$ period. Cells were then collected by centrifugation and the pellet was then lysated by heating at $95^{\circ} \mathrm{C}$ for $5 \mathrm{~min}$ in $1 \% \mathrm{SDS}$, and immediately cooled at $4^{\circ} \mathrm{C}$ for 15 min with ice-cold lysis buffer (50 mM Hepes, pH 7.5; $150 \mathrm{mM} \mathrm{NaCl} ; 10 \%$ glycerol; $1 \%$ triton X-100; $5 \mathrm{mM}$ EGTA; $1.5 \mathrm{mM} \mathrm{MgCl} 2 ; 20 \mathrm{mM}$ $\mathrm{Na}_{4} \mathrm{P}_{2} \mathrm{O}_{7} ; 20 \mathrm{mM} \mathrm{Na}_{3} \mathrm{VO}_{4} ; 50 \mu \mathrm{g} / \mathrm{mL}$ aprotinin and $4 \mathrm{mM}$ phenylmethylsulfonyl fluoride). After centrifugation $(15,000 \mathrm{~g}$, $15 \mathrm{~min}, 4^{\circ} \mathrm{C}$ ) to separate cellular debris, the lysates were resolved in a 12\% SDS-PAGE, and electrotransferred onto nitrocellulose paper (Protran; Schleicher and Schuell, Dassel, Germany). Primary antibodies rose against pAkt, pERK, pJNK and glyceraldehyde 3-phosphate dehydrogenase (GAPDH) (all from Cell Signaling, dilution 1:1000), were applied overnight at $4{ }^{\circ} \mathrm{C}$, and were detected using alkaline phosphatase-conjugated secondary antibodies (dilution 1:20000). Immunoreactive bands were detected with a western-light chemiluminescence detection system (ECL; APBiotech, Little Chalfont, UK) and photographed (HyperfilmECL; APBiotech). Immunoreactive bands were scanned with a GelDoc system (Bio-Rad, Hercules, Calif., USA) and optical density was determined with the ImageJ software (National Institutes of Health, Bethesda, MD, USA).

\section{Statistics}

Statistical analysis was performed with the non-parametric Mann-Whitney test. Statistical significance was established at $P<0.05$.

\section{Abbreviations}

GH: Growth hormone; GHR: Growth hormone receptor; CNS: Central nervous system; SGZ: Subgranular zone; DG: Dentate gyrus; NSC: Neural stem cells; IGF1: Insulin-like growth factor-1; GFAP: Glial fibrilar acidic protein; BrdU: 5-bromo-2'-deoxyuridine; ERK: Extracellular signal-regulated kinases; MEK1/ 2: Mitogen-activated protein kinase kinase; PI-3 K: Phosphoinositide -3kinase; Akt: Protein kinase B; mTOR: Mammalian target of rapamycine; IRS1: Insulin receptor substrate 1; PDK1: Phosphoinositide-dependent kinase-1; JNK: c-Jun N-teminal kinases; JAK2: Janus kinase 2; STAT5: Signal transducer and activator of transcription 5; MAPK: Mitogen activated protein kinase; mTORC1: Mammalian target of rapamycine complex 1; mTORC2: Mammalian target of rapamycine complex 2; GPCR: G protein-coupled receptor; EGF: Epidermal growth factor;
}

FGF2: Fibroblast growth factor 2; TUNEL: Terminal deoxy-nucleotidyl transferase dUTP nick-end labeling.

\section{Competing interests}

PD and CA work as researchers funded by Foundation Foltra dedicated to rehabilitation of patients suffering from neurological diseases. JD is the Scientific Director of Foundation Foltra which supports the Medical Center Project Foltra.

\section{Authors' contributions}

PD carried out the proliferation and survival studies (cultures, treatments, immunohistochemistry, western blots) and carried out the statistics. FA, SX and CA participated in the proliferation and survival studies. JD conceived of the study, and participated in its design and drafted the manuscript. JOM participated in the design of the study and its coordination. VMA conceived of the study, and participated in its design and drafting of the manuscript. All authors read and approved the final manuscript.

\section{Authors' information}

PD: PhD, researcher in Foundation Foltra. FA: PhD, researcher in the Neuroprotection and Neurogenesis in Brain Repair Group, Center for Neuroscience and Cell Biology, School of Medicine, University of Coimbra. $\mathrm{SX}: \mathrm{PhD}$, researcher in the Neuroprotection and Neurogenesis in Brain Repair Group, Center for Neuroscience and Cell Biology, School of Medicine, University of Coimbra. CA. Researcher in Foundation Foltra and PhD student at the University of Santiago de Compostela. JD: MD, PhD, Professor of Physiology, Scientific Director of Foundation Foltra, Professor Ad Honorem of the University of Santiago de Compostela. JOM: PhD, Head of the Neuroprotection and Neurogenesis in Brain Repair Group, Center for Neuroscience and Cell Biology, School of Medicine, University of Coimbra. VMA: MD, PhD, Professor of Physiology at the School of Medicine of the University of Santiago de Compostela.

\section{Acknowledgements}

The technical help of Sofia Grade, Tiago Silva and Raquel Ferreira is acknowledged.

This study was supported by Xunta de Galicia (Axudas para a Consolidación de Grupos de Investigación), Foundation Foltra (Teo, Spain) and the University of Coimbra (Portugal).

\section{Author details}

${ }^{1}$ Department of Physiology, School of Medicine, University of Santiago de Compostela, 15710 Santiago de Compostela, Spain. ${ }^{2}$ Neuroprotection and Neurogenesis in Brain Repair Group, Center for Neuroscience and Cell Biology, School of Medicine, University of Coimbra, 3004-517 Coimbra, Portugal. ${ }^{3}$ Medical Center Proyecto Foltra, Travesía de Montouto 24, 15886 Teo, Spain.

Received: 13 January 2014 Accepted: 15 August 2014

Published: 26 August 2014

\section{References}

1. Altman J, Das GD: Autoradiographic and histological evidence of postnatal hippocampal neurogenesis in rats. J Comp Neurol 1965, 124:319-335.

2. Kempermann G, Kuhn HG, Gage FH: Genetic influence on neurogenesis in the dentate gyrus of adult mice. Proc Natl Acad Sci U S A 1997, 94:10409-10414

3. Gage FH: Stem cells of the central nervous system. Curr Opin Neurobiol 1998, 8:671-676

4. Markakis EA, Gage FH: Adult-generated neurons in the dentate gyrus send axonal projections to field CA3 and are surrounded by synaptic vesicles. J Comp Neurol 1999, 406:449-460.

5. Zhao C, Deng W, Gage FH: Mechanisms and functional implications of adult neurogenesis. Cell 2008, 132:645-660.

6. Gage FH, Temple S: Neural stem cells: generating and regenerating the brain. Neuron 2013, 80:588-601.

7. Abdipranoto A, Wu S, Stayte S, Vissel B: The role of neurogenesis in neurodegenerative diseases and its implications for therapeutic development. CNS Neurol Disord Drug Targets 2008, 7:187-210. 
8. Abdipranoto-Cowley A, Park JS, Croucher D, Daniel J, Henshall S, Galbraith S, Mervin K, Vissel B: Activin A is essential for neurogenesis following neurodegeneration. Stem Cells 2009, 27:1330-1346.

9. Liu J, Solway K, Messing RO, Sharp FR: Increased neurogenesis in the dentate gyrus after transient global ischemia in gerbils. J Neurosci 1998, 18:7768-7778.

10. Magavi SS, Leavitt BR, Macklis JD: Induction of neurogenesis in the neocortex of adult mice. Nature 2000, 405:951-955.

11. Parent JM, Yu TW, Leibowitz RT, Geschwind DH, Sloviter RS, Lowenstein DH: Dentate granule cell neurogenesis is increased by seizures and contributes to aberrant network reorganization in the adult rat hippocampus. J Neurosci 1997, 17:3727-3738.

12. $\mathrm{Mu}$ Y, Lee SW, Gage FH: Signaling in adult neurogenesis. Curr Opin Neurobiol 2010, 20:416-423.

13. van Praag $H$, Kempermann G, Gage FH: Running increases cell proliferation and neurogenesis in the adult mouse dentate gyrus. Nat Neurosci 1999, 2:266-270.

14. van Praag $H$, Schinder AF, Christie BR, Toni N, Palmer TD, Gage FH: Functional neurogenesis in the adult hippocampus. Nature 2002, 415:1030-1034.

15. Devesa J, Devesa P, Reimunde P: Growth hormone revisited. Med Clin (Barc) 2010, 135:665-670.

16. Devesa J, Reimunde P, Devesa A, Souto S, Lopez-Amado M, Devesa P Arce VM: Recovery from neurological sequelae secondary to oncological brain surgery in an adult growth hormone-deficient patient after growth hormone treatment. J Rehabil Med 2009, 41:775-777.

17. High WM Jr, Briones-Galang M, Clark JA, Gilkison C, Mossberg KA, Zgaljardic DJ, Masel BE, Urban RJ: Effect of growth hormone replacement therapy on cognition after traumatic brain injury. J Neurotrauma 2010, 27:1565-1575

18. Reimunde $P$, Quintana A, Castañón B, Casteleiro N, Vilarnovo Z, Otero A, Devesa A, Otero-Cepeda XL, Devesa J: Effects of growth hormone (GH) replacement and cognitive rehabilitation in patients with cognitive disorders after traumatic brain injury. Brain Inj 2011, 25:65-73.

19. Devesa J, Reimunde P, Devesa P, Barberá M, Arce V: Growth hormone (GH) and brain trauma. Horm Behav 2013, 63:331-344.

20. Aberg DN, Lind J, Isgaard J, Georg Kuhn H: Peripheral growth hormone induces cell proliferation in the intact adult rat brain. Growth Horm IGF Res 2010, 20:264-269.

21. Christophidis LJ, Gorba T, Gustavsson M, Williams CE, Werther GA, Russo VC, Scheepens A: Growth hormone receptor immunoreactivity is increased in the subventricular zone of juvenile rat brain after focal ischemia: a potential role for growth hormone in injury-induced neurogenesis. Growth Horm IGF Res 2009, 19:497-506.

22. Scheepens A, Sirimanne ES, Breier BH, Clark RG, Gluckman PD, Williams CE: Growth hormone as a neuronal rescue factor during recovery from CNS injury. Neuroscience 2001, 104:677-687.

23. Devesa P, Reimunde P, Gallego R, Devesa J, Arce V: Growth hormone (GH) treatment may cooperate with locally-produced $\mathrm{GH}$ in increasing the proliferative response of hippocampal progenitors to kainate-induced injury. Brain Inj 2011, 25:503-510.

24. Heredia M, Fuente A, Criado J, Yajeya J, Devesa J, Riolobos AS: Early growth hormone $(\mathrm{GH})$ treatment promotes relevant motor functional improvement after severe frontal cortex lesion in adult rats. Behav Brain Res 2013, 247:48-58.

25. Argetsinger LS, Carter-Su C: Mechanism of signaling by growth hormone receptor. Physiol Rev 1996, 76:1089-1107.

26. Kopchick JJ, Andry JM: Growth hormone (GH), GH receptor and signal transduction. Mol Genet Metab 2000, 71:293-314.

27. Costoya JA, Finidori J, Moutoussamy S, Señaris R, Devesa J, Arce VM: Activation of growth hormone receptor delivers an antiapoptotic signal: evidence for a role of Akt in this pathway. Endocrinology 1999, 140:5937-5943.

28. Hayashi AA, Proud CG: The rapid activation of protein synthesis by growth hormone requires signaling through mTOR. Am J Physiol Endocrinol Metab 2007, 292:E1647-E1655.

29. Dunlop EA, Tee AR: Mammalian target of rapamycin complex 1: signalling inputs, substrates and feedback mechanisms. Cell Signal 2009, 21:827-835

30. Dowling RJ, Topisirovic I, Fonseca BD, Sonenberg N: Dissecting the role of mTOR: lessons from mTOR inhibitors. Biochim Biophys Acta 1804, 2010:433-439.
31. Barca O, Ferré S, Seoane M, Prieto JM, Lema M, Señarís R, Arce VM: Interferon beta promotes survival in primary astrocytes through phosphatidylinositol 3-kinase. J Neuroimmunol 2003, 139:155-159.

32. Barca $O$, Seoane $M$, Ferré $S$, Prieto JM, Lema M, Señarís $R$, Arce VM: Mechanisms of interferon-beta-induced survival in fetal and neonatal primary astrocytes. Neuroimmunomodulation 2007, 14:39-45.

33. Ling L, Zhu T, Lobie PE: Src-Crkll-C3G-dependent activation of Rap1 switches growth hormone-stimulated p44/42 MAP kinase and JNK/SAPK activities. J Biol Chem 2003, 278:27301-27311.

34. Tripathi A, Sodhi A: Growth hormone-induced production of cytokines in murine peritoneal macrophages in vitro: role of JAK/STAT, PI3K, PKC and MAP kinases. Immunobiology 2009, 214:430-440.

35. Arce VM, Devesa P, Devesa J: Role of growth hormone $(\mathrm{GH})$ in the treatment of neural diseases: from neuroprotection to neural repair. Neurosci Res 2013, 76:179-186.

36. Gustafson K, Hagberg H, Bengtsson BA, Brantsing C, Isgaard J: Possible protective role of growth hormone in hypoxia-ischemia in neonatal rats. Pediatr Res 1999, 45:318-323.

37. Blackmore DG, Golmohammadi MG, Large B, Waters MJ, Rietze RL: Exercise increases neural stem cell number in a growth hormone-dependent manner, augmenting the regenerative response in aged mice. Stem Cells 2009, 27:2044-2052.

38. Blackmore DG, Vukovic J, Waters MJ, Bartlett PF: GH mediates exercisedependent activation of SVZ neural precursor cells in aged mice. PLoS One 2012, 7:e49912.

39. Blackmore DG, Reynolds BA, Golmohammadi MG, Large B, Aguilar RM, Haro L, Waters MJ, Rietze RL: Growth hormone responsive neural precursor cells reside within the adult mammalian brain. Sci Rep 2012, 2:250.

40. Pathipati P, Gorba T, Scheepens A, Goffin V, Sun Y, Fraser M: Growth hormone and prolactin regulate human neural stem cell regenerative activity. Neuroscience 2011, 190:409-427.

41. McLenachan S, Lum MG, Waters MJ, Turnley AM: Growth hormone promotes proliferation of adult neurosphere cultures. Growth Horm IGF Res 2009, 19:212-218.

42. Regalado-Santiago C, López-Meraz ML, Santiago-García J, FernándezPomares C, Juárez-Aguilar E: Growth hormone $(\mathrm{GH})$ is a survival rather than a proliferative factor for embryonic striatal neural precursor cells. Growth Horm IGF Res 2013, 23:179-186.

43. Paliouras GN, Hamilton LK, Aumont A, Joppé SE, Barnabé-Heider F, Fernandes $\mathrm{KJ}$ : Mammalian target of rapamycin signaling is a key regulator of the transit-amplifying progenitor pool in the adult and aging forebrain. J Neurosci 2012, 32:15012-15026.

44. Zoncu R, Efeyan A, Sabatini DM: mTOR: from growth signal integration to cancer, diabetes and ageing. Nat Rev Mol Cell Biol 2011, 12:21-35.

45. Sarbassov DD, Guertin DA, Ali SM, Sabatini DM: Phosphorylation and regulation of Akt/PKB by the rictor-mTOR complex. Science 2005, 307:1098-1101.

46. Davis RJ: Signal transduction by the JNK group of MAP kinases. Cell 2000, 103:239-252.

47. Yamauchi J, Miyamoto Y, Sanbe A, Tanoue A: JNK phosphorylation of paxillin, acting through the Rac1 and Cdc42 signaling cascade, mediates neurite extension in N1E-115 cells. Exp Cell Res 2006, 312:2954-2961.

48. Wang X, Fu S, Wang Y, Yu P, Hu J, Gu W, Xu XM, Lu P: Interleukin-1 beta mediates proliferation and differentiation of multipotent neural precursor cells through the activation of SAPK/JNK pathway. Mol Cell Neurosci 2007, 36:343-354.

49. Hong YK, Lee NG, Lee MJ, Park MS, Choi G, Suh YS, Han SY, Hwang S, Jeong $\mathrm{G}$, Cho KS: dXNP/DATRX increases apoptosis via the JNK and dFOXO pathway in Drosophila neurons. Biochem Biophys Res Commun 2009 384:160-166.

50. Qu C, Li W, Shao Q, Dwyer T, Huang H, Yang T, Liu G: c-Jun N-terminal kinase 1 (JNK1) is required for coordination of netrin signaling in axon guidance. J Biol Chem 2012, 288:1883-1895.

51. Zhu T, Goh EL, LeRoith D, Lobie PE: Growth hormone stimulates the formation of a multiprotein signaling complex involving p130(Cas) and Crkll. Resultant activation of c-Jun N-terminal kinase/stress-activated protein kinase (JNK/SAPK). J Biol Chem 1998, 273:33864-33875.

52. Minoia M, Gentilin E, Molè D, Rossi M, Filieri C, Tagliati F, Baroni A, Ambrosio MR, Degli Uberti E, Zatelli MC: Growth hormone receptor blockade inhibits growth hormone-induced chemoresistance by restoring cytotoxic-induced apoptosis in breast cancer cells independently of estrogen receptor expression. J Clin Endocrinol Metab 2012, 97:E907-E916. 
53. Turnley AM, Faux CH, Rietze RL, Coonan JR, Bartlett PF: Suppressor of cytokine signaling 2 regulates neuronal differentiation by inhibiting growth hormone signaling. Nat Neurosci 2002, 5:1155-1162.

54. Donahue CP, Jensen RV, Ochiishi T, Eisenstein I, Zhao M, Shors T, Kosik KS: Transcriptional profiling reveals regulated genes in the hippocampus during memory formation. Hippocampus 2002, 12:821-833.

55. Donahue CP, Kosik KS, Shors TJ: Growth hormone is produced within the hippocampus where it responds to age, sex, and stress. Proc Natl Acad Sci U S A 2006, 103:6031-6036.

56. Sun LY, Al-Regaiey K, Masternak MM, Wang J, Bartke A: Local expression of GH and IGF-1 in the hippocampus of GH-deficient long-lived mice. Neurobiol Aging 2005, 26:929-937.

57. Agasse F, Roger M, Coronas V: Neurogenic and intact or apoptotic non- neurogenic areas of adult brain release diffusible molecules that differentially modulate the development of subventricular zone cell cultures. Eur J Neurosci 2004, 19:1459-1468.

doi:10.1186/1471-2202-15-100

Cite this article as: Devesa et al:: Growth hormone pathways signaling for cell proliferation and survival in hippocampal neural precursors from postnatal mice. BMC Neuroscience 2014 15:100.

\section{Submit your next manuscript to BioMed Central and take full advantage of:}

- Convenient online submission

- Thorough peer review

- No space constraints or color figure charges

- Immediate publication on acceptance

- Inclusion in PubMed, CAS, Scopus and Google Scholar

- Research which is freely available for redistribution 